\title{
Current trends in economy, sustainable development, and energy: a circular economy view
}

\author{
Ramón Sanguino $^{1}$ - Ascensión Barroso ${ }^{2}$ - Santiago Fernández-Rodríguez ${ }^{2} \cdot$ María Isabel Sánchez-Hernández $^{2}$
}

Published online: 7 January 2020

(C) Springer-Verlag GmbH Germany, part of Springer Nature 2020

\section{Introduction}

Nowadays, it is widely recognized that the current production and consumption models are no longer adequate because of the inefficient use of resources (especially energy) and its dramatical consequences, environmental load and social inequality (UNEP 2011). In this context, Circular Economy (CE) has started to be considered a sustainable economic paradigm (Geissdoerfer et al. 2017), enabled by novel business models (Lewandowski 2016) and responsible consumers (Borrello et al. 2017).

As highlighted by McDowall et al. 2017), the origin of the concept emerged in Europe in the 1980s and 1990s, together with early policies of the European Union member states, drawing on ideas that can be traced to the 1970s. Driven by a desire to divert waste from landfill, the Netherlands and Germany pioneered concepts of waste prevention and reduction, with the waste hierarchy introduced to the Dutch Parliament in 1979. However, even acknowledging that CE was rooted in environmental economics, there is today a huge interdisciplinary framework underpinning $\mathrm{CE}$. This new framework offers

\section{Responsible editor: Philippe Garrigues}

Ramón Sanguino

sanguino@unex.es

Ascensión Barroso

abarrosom@unex.es

Santiago Fernández-Rodríguez

santiferro@unex.es

María Isabel Sánchez-Hernández

isanchez@unex.es

1 Department of Construction, School of Technology, University of Extremadura, Cáceres, Spain

2 Department of Business Management and Sociology, Faculty of Economic and Business Sciences, University of Extremadura, Badajoz, Spain good prospect for gradual involvement of the present economic system, including production and consumption models. We can say that at the moment, $\mathrm{CE}$ has the supreme goal of promoting sustainable development through the dissociation of environmental pressure from economic growth (Ghisellini et al. 2016; Schandl et al. 2016; Bruel et al. 2019).

According to Ghisellini et al. (2016), CE is a new economic system aiming to increase the efficiency of resource use to achieve improvements in the existing balance between economy, environment and society. In this line, the concept of CE has recently been proposed as a new development strategy that aims to mitigate the contradiction between the rapid economic growth and the shortage of raw materials and energy (Christis et al. 2019).

Although there is no commonly accepted definition of CE so far, the core of CE is the closed flow of materials and the use of raw materials and energy through multiple phases (Gan et al. 2013). The ' $3 R$ ' principles-reduction, reuse, and recycling of materials and energy - are often cited to describe the three possible approaches in practice (the goals of reduce, reuse, and especially recycle have become the only acceptable ways of disposing of waste (Yong 2007, Yellishetty et al. 2011, Samiha 2013, Ahmadi 2017, Huang et al. 2018). This concept has been pursued by many countries' environmental policy makers as a potential strategy to solve existing environmental problems (Preston and Carr 2018). As one of the main objectives of governments is to promote the sustainable development of economy and society, it also helps to achieve sustainable environmental protection (Yuan et al. 2006).

Once the high economic potential of CE has been recognized, in the European Union, different CE Action Plans have been proposed as new initiatives, changes or adaptations to legislation, mainly related to waste and landfills at the beginning. In 2015, a range of policy measures collectively known as the Circular Economy Package, and later replaced by the Closing the Loop-An Action Plan for the CE, were approved in Europe (COM 2015). At present times the CE is a priority for Europe. Nearly 1 billion from Horizon 2020's final Work 
Programme (2018-2020) is being invested into research, innovation and financing of projects and initiatives supporting the European CE ambitions (COM 2017). In 2018, the European Commission adopted an ambitious CE package covering the whole cycle: production, consumption, waste management and secondary raw materials (COM 2018). On 4 March 2019, the $\mathrm{CE}$ was fully completed, and the European Commission adopted a comprehensive report on the implementation of the CE Action Plan (COM 2019). The report presented the main achievements until now and sketched out future challenges to shaping the European economy and paving the way towards a climate-neutral economy characterized by minimizing pressure on natural and freshwater resources as well as ecosystems. Table 1 shows the main key initiatives (COM 2015) in line with McDowall et al. 2017) and the achievements (COM 2019) of the $\mathrm{CE}$ in Europe.

The CE has received increased attention in the academic research with a range of reviews on the topic. More explicitly, the current literature explores the nexus among economic growth and environmental problems such as contamination (Ssali et al. 2018), pollution (Sarkodie and Strezov 2019), climate change (Goldstone 2018), greenhouse gas discharges (Zhu et al. 2016) or global warming (Wang et al. 2017) between others. Specific areas of attention are closed loop value and supply chains, circular business models and circular product design (Geissdoerfer et al. 2017).

As most researchers working on this topic have backgrounds in environmental engineering, chemical engineering, and mineral process engineering (Yuan et al. 2006), we propose the current special issue. This special issue aims to contribute to the literature on Economy, Sustainable Development and Energy in the context of the New Circular Economy View, by presenting a set of eclectic contributions that are unveiling different dimensions of this complex and still unexplored problematic, especially concerning the challenges raised by the European Commission.

\section{Special issue content}

The present special issue by Ramón Sanguino, Ascensión Barroso, Santiago Fernández-Rodríguez, and M. Isabel Sánchez-Hernández, from the University of Extremadura in Spain, features eight scientific contributions and offers a selection of distinct scholar and research methods. The authors are from different countries: Denmark, Lithuania, Nigeria, Pakistan, Poland, Singapore, Spain and the UK.

The introductory article to this special issue summarizes the results of an extensive review of research methods. The first three articles are related to the construction sector, the waste management. The next three articles are empirical test studies carried out with bacteria and laboratory elements. The last two articles focus on software adaptations and their best use in the context of the CE.
The first article, Promotion of Circular Economy: steelwork dusts as secondary raw material in conventional mortars by Lozano-Lunar et al. (2019), provides an example of promotion of Circular Economy in the use of waste as a secondary raw material (SRM). The paper analyses the use of electric arc furnace dust (EAFD) as SRM in conventional mortar production for its use as a construction material. Their main results indicate a slight improvement in mechanical behaviour with the incorporation of EAFD, the reason why its use as SRM in conventional mortars would benefit the construction industry and would encourage the CE.

Related with this sector, the second article, Recommendations for the management of Construction and Demolition Waste in treatment plants by Barbudo et al. (2019), suggests some recommendations for the management of construction and demolition waste (CDW) in treatment plants. CDW consists approximately of one third waste generated in the European Union. The recycling of this stream waste will provide ecological and sustainable benefits. Recycled aggregates from construction and demolition waste are clearing a path into civil constructions, as substitutes for natural aggregates. CDW has been upgraded to a priority waste stream status in the EU. Directive (2008/98/CE), to promote CDW reuse, recycling and other recovery operations, establishes a minimum of $70 \%$ in weight of these activities by 2020. This waste is usually transported to a CDW treatment plant, where it is managed and treated for their subsequent disposal at landfills or reuse as recycled aggregate (RA). The mean of recycling rate or the EU members, determined by the percentage of total produced $\mathrm{CDW}$ that is processed as recycled aggregate (RA), is over $40 \%$, whereas in Spain this recycling rate does not reach $15 \%$. Rodriguez-Robles et al. (2015) concluded that, in Spain, one of the obstacles, apart from the administrative theme, is the lack of confidence in the product given the differences between the RA produced in the CDW treatment plants. The paper intends to address handling recommendations in CDW treatment plants to obtain recycled aggregates (RA) that guarantee enough quality in its implementation and disclose good practices in the management of the CDW that must be carried out and also highlights the importance of publicize the obligations of each of the agents involved in the management of the CDW.

Their main handling recommendations from a sample of 13 authorized treatment plants, located in central Andalusia, are summarized in the following proposal: Selective demolition; Weighing and classification of the CDW; Destination of CDW according the classification and CDW treatment line (pretreatment, primary treatment, secondary treatment; finally, the manufacturer must establish a quality control system in the production of RA, based on EN 13242 standard for their use in civil engineering work and road construction.

Furthermore, an important application is the efficiency of the solar collector installation in buildings. In this way, 
Table 1 Summary of the EU action plan for the CE

\begin{tabular}{|c|c|c|}
\hline Area & Specific policies and examples (COM 2015) & Achievements (COM 2019) \\
\hline Production & $\begin{array}{l}\text { Eco-design: proposal to adapt the existing } \\
\text { eco-design work plan to incorporate durability, } \\
\text { reparability and recyclability criteria. } \\
\text { Cleaner manufacturing }\end{array}$ & $\begin{array}{l}\text { The implementation of the Eco-design Working Plan } \\
\text { 2016-2019 }\end{array}$ \\
\hline Consumption & $\begin{array}{l}\text { Proposed introduction of product labelling for } \\
\text { durability. } \\
\text { Pricing: member states are 'encouraged' to use } \\
\text { pricing instruments. } \\
\text { Consumer protection rules: e.g. guarantee periods }\end{array}$ & $\begin{array}{l}\text { The increase the effectiveness of the EU Ecolabel to offer } \\
\text { consumers accurate environmental information. } \\
\text { The Product Environmental Footprint (PEF) and } \\
\text { Organization Environmental Footprint (OEF) } \\
\text { methods developed by the Commission. }\end{array}$ \\
\hline $\begin{array}{l}\text { Waste management and boosting } \\
\text { markets for secondary materials }\end{array}$ & $\begin{array}{l}\text { New legislative proposals on waste and landfills, } \\
\text { including new binding targets. } \\
\text { Proposed changes to extend produce responsibility } \\
\text { rules to reward products that are designed for } \\
\text { easier repair, remanufacture or recycling. } \\
\text { Clarifying legal rules on definitions of 'waste'; } \\
\text { proposed standards for various secondary } \\
\text { materials to foster markets }\end{array}$ & $\begin{array}{l}\text { A revised waste legislative framework entered into force } \\
\text { in July } 2018 \text { for turning waste into products: e.g. } \\
\text { reinforced rules and new obligations on separate } \\
\text { collection (biowaste, textiles and hazardous waste } \\
\text { produced by households, construction and demolition } \\
\text { waste. }\end{array}$ \\
\hline Priority areas & $\begin{array}{l}\text { Five priority areas are identified: plastics, food } \\
\text { waste, critical raw materials, } \\
\text { construction/demolition waste, biomass and } \\
\text { bioproducts }\end{array}$ & The 2030 Agenda for Sustainable Development \\
\hline $\begin{array}{l}\text { Innovation, investment and } \\
\text { 'horizontal' measures }\end{array}$ & $\begin{array}{l}\text { Funding for research and innovation under Europe's } \\
\text { Horizon } 2020 \text { program and also through the } \\
\text { cohesion policy }\end{array}$ & $\begin{array}{l}\text { Nearly } 1 \text { billion from Horizon 2020's final Work } \\
\text { Programme (2018-2020) is being invested into } \\
\text { research, innovation and financing CE projects }\end{array}$ \\
\hline Monitoring progress & $\begin{array}{l}\text { The action plan refers to the resource efficiency } \\
\text { scoreboard and raw materials scoreboard, with } \\
\text { commitments to develop new indicators for a } \\
\text { range of CE topics }\end{array}$ & $\begin{array}{l}\text { The EU monitoring framework for the CE presented by } \\
\text { the Commission in } 2018 \text { includes ten key indicators } \\
\text { covering each phase of the lifecycle of products as } \\
\text { well as competitiveness aspects }\end{array}$ \\
\hline
\end{tabular}

the next paper, Analysis of an efficiency of the solar collector installation in a small public building in Poland, Lithuania and Spain: a case of study by Krawczyk et al. (2019), analyses that issue in some small public buildings in Poland, Lithuania and Spain, in the bases of a case study. In most European countries, a solar collector market is at the stage of continuous development; however its expansion rate differs. It shows that much more factors than only the local solar radiation is important, including a technology progress, costs, local manufactures' engagement, an economic government support or an environmentally consciousness raising relevant to a mitigating climate change. The authors conducted the analysis for a public office building, with a few toilets and a social room, used by 54 people. As a primary heat source for HVAC and DHW systems, an oil boiler was used, whereas solar collectors were considered as an energy source for hot water preparation. The study was made in three locations of the building: Bialystok (Poland), Córdoba (Spain) and Kaunas (Lithuania). The average daily global radiation on the horizontal surface is different. Estimation of solar energy gains and collector efficiency was conducted using a simulation software delivered within the framework of VIPSKILLS project. It was found that beam solar radiation share in a total radiation balance was nearly twice higher in Córdoba for solar collectors installed with the tilt angle between 15 and $35^{\circ}$. In case of Bialystok and Kaunas, the efficiency was similar (46$47 \%$ ), and the recommended tilt angle was in a range $30-40^{\circ}$.

The fourth article, Microwave support of the alcoholic fermentation process of cyanobacteria Arthrospira platensis by Nowicka et al. (2019), presents the case for the effect of thermal hydrolysis on degradation of polysaccharides contained in biomass of cyanobacteria Arthrospira platensis. The paper aimed at the selection of the most advantageous parameters of thermos hydrolysis to reach the experiment variant with the best effects, effectiveness of alcohol fermentation. Although the literature provides examples of application of microwaves as a conditioning factor of alcohol fermentation, substrate exposure to microwave radiation in various temperature ranges has shown that microwaves increase solubilization of substrates and break the network of exopolysaccharides, thereby speeding up chemical processes.

The fifth article is Purification of post-fermentation effluent using Chlorella vulgaris microalgae by Szwarc et al. (2019). The authors focus on the use of effluent formed in the process of anaerobic decomposition of organic substances as a 
medium in the processes of Chlorella vulgaris algae biomass multiplication in a flow-through system. The experiment assumed a continuous supply of post-fermentation effluent with a simultaneous reception of the culture mixture. Their main results show us the efficiency of nutrient removal translated into the final biomass content of the tested microalgae. The use of the tested wastewater significantly reduced the need for the use of chemical reagents. The contents of nitrogen and phosphorus found in wastewater were sufficient to conduct an efficient algae culture.

The next article, in situ Regeneration of Activated Carbon using Electric Potential Swing Desorption (EPSD) for CO2 and H2S Removal from Biogas by Farooq et al. (2019), shows more efficient and economic process. Based on current biodegradable resources, the authors demonstrate that the electric potential swing desorption (ESPD) system has inherent advantages over other technologies for in situ regeneration of activated carbons.

The seventh article, Accuracy enhancement for land cover classification using LiDAR and multitemporal Sentinel 2 images in a forested watershed by Fragoso-Campón et al. (2019), exposed the accuracy enhancement for land cover classification using LiDAR and multitemporal Sentinel 2 images in a forested watershed. It is important to highlight that mapping land cover with high accuracy has become a reality with the application of current remote sensing techniques. Additionally, the accuracy of satellite imagery classification can be improved using multitemporal series combined with LiDAR data. The obtained results show that overall accuracy is better if LiDAR data is included in the land cover classification. This improvement can be a significant issue in land cover classification of forest watershed due to relationship and influence that vegetation cover has on runoff estimation. Therefore, LiDAR data, from National Plan of Aerial Ortho-photography of the Spanish National Geographic Institute, is a good improvement for data fusion analysis.

Related with the explained before, erosion is one of the major problems all over the world, also in Nigeria and Lagos State in particular. In the final article, The Application of Remote Sensing and GIS Technology to Erosion Risk Mapping, developed by Makinde and Oyebanji (2019), the objectives of the research were to identify land use/land cover changes in Eti-Osa LGA and estimate actual erosion risk using Revised Universal Soil Loss Equation (RUSLE) model. In addition, the paper evaluates the perception of communities within the study area with the view of understanding the risk involved in erosion. Their main results showed that the sediment yield of the study was estimated to be between 0 to $48 \mathrm{ton} / \mathrm{ha} / \mathrm{yr}$. Highly erosive rainfall, poor cover management and support practices, sand filling and land clearing in Eti-Osa for urbanization and infrastructure development have resulted in widespread soil erosion over the land surface is one of the main conclusions. The extent of soil erosion occurring in the area is still increasing and is now a major cause for concern. The RUSLE model was combined with RS and GIS techniques to analyse the annual average soil loss rates caused by the various factors which influence soil erosion (Table 2).

\section{Final remarks}

The strengths of this special issue are undoubtedly the variety of topics, contexts and research methodologies covered within

Table 2 Overview of the articles in this special issue

\begin{tabular}{|c|c|c|c|}
\hline Article & Approach & Sector/topic & Contribution/key findings \\
\hline 1-Lozano-Lunar et al. & Reusing & Construction: secondary raw materials & $\begin{array}{l}\text { Steelwork dusts as secondary raw material could } \\
\text { contribute to implement } \mathrm{CE} \text { in construction } \\
\text { engineering }\end{array}$ \\
\hline 2-Barbudo et al. & Recycling & Construction: demolition waste & $\begin{array}{l}\text { Contribution to CE by handling of construction and } \\
\text { demolition waste in treatment plants }\end{array}$ \\
\hline 3-Krawczyk et al. & Reduction & Renewable energy & $\begin{array}{l}\text { Energy efficiency and air quality in civil constructions } \\
\text { are possible under the CE principles }\end{array}$ \\
\hline 4-Nowicka et al. & Reusing & Biomass & $\begin{array}{l}\text { Demonstrating higher efficiency when comparing } \\
\text { biomass and biofuel }\end{array}$ \\
\hline 5-Szwarc et al. & Recycling and reusing & Wastewater & Experiment successfully using effluents \\
\hline 6-Farooq et al. & Reduction & Biodegradable resources & Energy reduction and cost-efficiency \\
\hline 7-Fragoso-Campón et al. & Preservation of resources & Environmental protection & $\begin{array}{l}\text { New technology for forest monitoring and flood } \\
\text { management prediction }\end{array}$ \\
\hline 8-Makinde and Oyebanji & Preservation of resources & Environmental protection & New technology for monitoring soil erosion \\
\hline
\end{tabular}


the current trends in economy, sustainable development and energy. They confirm the increasing interest for practitioners and researchers in CE issues, as well as the potential of this stream of research to influence in $\mathrm{CE}$ and other related studies.

This special issue, based in the published articles, highlights the recent scientific evidences that are being made in the academic context in order to follow the strategy for reducing the entry of materials such as the production of original waste to close the loops or economic and ecological flows of resources. Although covering more complex topics, the authors have tried to write the papers in an understandable way. The issue as a whole enhanced from a practical view of the CE goals of reduce, reuse and recycle extensively defended academic literature in the last years (Yuan et al. 2006, Yong 2007, Yellishetty et al. 2011, Samiha 2013, Ghisellini et al. 2016, Schandl et al. 2016, Ahmadi 2017, Geissdoerfer et al. 2017, Huang et al. 2018, Preston and Carr 2018, Bruel et al. 2019).

It has been widely recognized that $\mathrm{CE}$ could help improve resource productivity and eco-efficiency, reform the management of the environment, and achieve sustainable development. Despite the growing importance amongst academics, CE must allow to reconcile environmental stewardship with business concerns, and for that purpose, the concept of CE and its underlying principles of reduce, reuse and recycle is not without challenges.

We believe this special issue will become a very used reference for future research in CE. The articles published in this special issue will be particularly useful to CE researchers, both in international papers written by renowned authors as in doing their own research. The articles will serve to demonstrate that value creation can still be achieved with strong planetary boundaries. The specific approaches to CE compiled in this special issue will serve also to inspire others to materialize the benefits of the CE into clear business opportunities.

Acknowledgements This review was possible thanks to the support of the University of Extremadura (Spain) and School of Technology, the Queen Margaret University (UK), and the Environment, Green Technology and Engineering International Conference (EGTEIC) in organizing the conference in Cáceres during 18th-20th of June 2018 and the Economy, Sustainable Development and Energy International Conference (ESDEIC), held from the 25th to the 27th of June 2018. Furthermore, we would like to thank the reviewers who contributed their valuable time and effort to improve the article's quality with much appreciated suggestions and comments.

\section{References}

Ahmadi M (2017) Evaluating the performance of 3Rs waste practices: case study-region one municipality of Tehran. Adv Recycling Waste Manag 2(130):2. https://doi.org/10.4172/2475-7675.10001

Barbudo A, Ayuso J, Lozano A, Cabrera M, López-Uceda A (2019) Recommendations for the management of construction and demolition waste in treatment plants. Environ Sci Pollut Res
Borrello M, Caracciolo F, Lombardi A, Pascucci S, Cembalo L (2017) Consumers' perspective on circular economy strategy for reducing food waste. Sustainability 9(1):141

Bruel A, Kronenberg J, Troussier N, Guillaume B (2019) Linking industrial ecology and ecological economics: a theoretical and empirical foundation for the circular economy. J Ind Ecol 23(1):12-21

Christis M, Athanassiadis A, Vercalsteren A (2019) Implementation at a city level of circular economy strategies and climate change mitigation - the case of Brussels. J Clean Prod 218:511-520

COM (2015) Circular economy: closing the loop. European Commission. Available at: https://ec.europa.eu/commission/sites/beta-political/ files/circular-economy-factsheet-general_en.pdf. [Accessed 12/09/ 2019]

COM (2017) Circular economy research and innovation. Connecting Economic \& Environmental Gains. Available at: https://ec.europa. eu/programmes/horizon2020 [Accessed 11/09/2019]

COM (2018) Circular Economy: Implementation of the Circular Economy Action Plan. Available at: http://ec.europa.eu/ environment/circular-economy/index_en.htm [Accessed 8/06/2019]

COM (2019) Report from the Commission to the European Parliament, the Council, the European Economic and Social Committee and the Committee of the Regions. Available at: https://eur-lex.europa.eu/ legal-content/EN/TXT/?uri=CELEX:52019DC0190 [Accessed 11/ 09/2019]

Farooq M, Almustapha MN, Imran M, Saeed MA, Andresen JM (2019) In-situ regeneration of activated carbon with electric potential swing desorption (EPSD) for the H2S removal from biogas. Environ Sci Pollut Res

Fragoso-Campón L, Quirós E, Mora J, Gutiérrez Gallego JA, DuránBarroso P (2019) Overstory-understory land cover mapping at the watershed scale: accuracy enhancement by multitemporal remote sensing analysis and LiDAR. Environ Sci Pollut Res

Gan Y, Zhang T, Liang S, Zhao Z, Li N (2013) How to Deal with resource productivity. J Ind Ecol 17:440-451

Geissdoerfer M, Savaget P, Bocken NMP, Hultink EJ (2017) The circular economy - a new sustainability paradigm? J Clean Prod 143:757768

Goldstone JA (2018) Demography, environment, and security. Environmental conflict. Routledge, London

Huang B, Wang X, Kua H, Geng Y, Bleischwitz R, Ren J (2018) Construction and demolition waste management in China through the 3R principle. Resour Conserv Recycl 129:36-44. https://doi.org/ 10.1016/j.resconrec.2017.09.029

Krawczyk DA, Żukowski M, Rodero A (2019) Efficiency of a solar collector system for the public building depending on its location. Environ Sci Pollut Res

Lewandowski M (2016) Designing the business models for circular economy. Towards the conceptual framework. Sustainability 8(1):43

Lozano-Lunar A, Barbudo A, Fernández JM, Jiménez JR (2019) Promotion of circular economy: steelwork dusts as secondary raw material in conventional mortars. Environ Sci Pollut Res

Makinde EO, Oyebanji EI (2019) The application of remote sensing and GIS technology to Erosion risk mapping. Environ Sci Pollut Res

McDowall W, Geng Y, Huang B, Barteková E, Bleischwitz R, Türkeli S, Kemp R, Doménech T (2017a) Circular economy policies in China and Europe. J Ind Ecol 21(3):651-661

Nowicka A, Zieliński M, Dębowski M (2019) Microwave support of the alcoholic fermentation process of cyanobacteria Arthrospira platensis. Environ Sci Pollut Res

Preston C, Carr W (2018) Recognitional justice, climate engineering, and the care approach. Ethics Pol Environ 21:308-323

Rodríguez-Robles D, García-González J, Juan-Valdés A, Morán-del Pozo JM, Guerra-Romero MI (2015) Overview regarding construction and demolition waste in Spain. Environ Technol 36:1-11 
Samiha B (2013) The importance of the 3R principle of municipal solid waste management for achieving sustainable development. Mediterr J Soc Sci 4(3):129-135

Sarkodie SA, Strezov V (2019) Effect of foreign direct investments, economic development and energy consumption on greenhouse gas emissions in developing countries. Sci Total Environ 646:862871. https://doi.org/10.1016/j.scitotenv.2018.07.36

Schandl H, Hatfield-Dodds S, Wiedmann T, Geschke A, Cai Y, West J, Newth D, Baynes T, Lenzen M, Owen A (2016) Decoupling global environmental pressure and economic growth: scenarios for energy use, materials use and carbon emissions. J Clean Prod 132:45-56

Ssali MW, Du J, Hongo DO, Mensah IA (2018) Impact of economic growth, energy use and population growth on carbon emissions in sub-Sahara Africa. JESE-B 7:178-192. https://doi.org/10.17265/ 2162-5263/2018.05.002

Szwarc K, Szwarc D, Zieliński M (2019) Removal of biogenic compounds from the post-fermentation effluent in a culture of Chlorella vulgaris. Environ Sci Pollut Res

UNEP - United Nations Environmental Programme (2011) Decoupling natural resource use and environmental impacts from economic growth. International Resource Panel. Sustainable Consumption and Production Branch. Available at: http://wedocs.unep.org [Accessed 8/06/2019]

Wang X, Jiang D, Lang X (2017) Future extreme climate changes linked to global warming intensity. Sci Bull 62(24):1673-1680. https://doi. org/10.1016/j.scib.2017.11.004

Yellishetty M, Mudd GM, Ranjith PG, Tharumarajah A (2011) Environmental life-cycle comparisons of steel production and recycling: sustainability issues, problems and prospects. Environ Sci Pol 14(6):650-663. https://doi.org/10.1016/j.envsci.2011.04. 008

Yong R (2007) The circular economy in China. J Mater Cycles Waste 9: $121-129$

Yuan Z, Bi J, Moriguichi Y (2006) The circular economy: a new development strategy in China. J Ind Ecol 10:4-8

Zhu H, Duan L, Guo Y, Yu K (2016) The effects of FDI, economic growth and energy consumption on carbon emissions in ASEAN5: evidence from panel quantile regression. Econ Model 58:237248. https://doi.org/10.1016/j.econmod.2016.05.003

Publisher's note Springer Nature remains neutral with regard to jurisdictional claims in published maps and institutional affiliations.

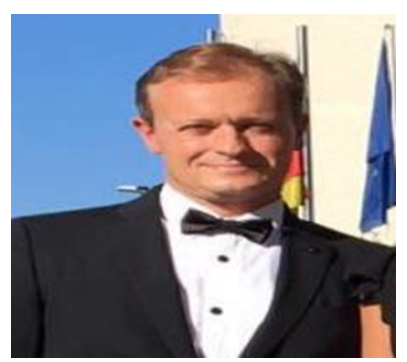

Ramón Sanguino Galván Teacher and Researcher at the University of Extremadura.

Doctor in the area of Business Management of the Department of Business Management and Sociology, Faculty of Economic and Business Sciences, since 1999.

He has recently published collaborative research work in impact factor journals as the Journal of Business Research, Sustainability, European Journal of International Management, Journal of Knowledge Management, Journal of Intellectual Capital, Internet Research, International Journal of Educational Technology and Higher Education, Journal of Family Business Strategy and International Journal of Environmental Research and Public Health.

$\mathrm{He}$ is the Chairman of ICETIC (Innovative and Creative Education and Technology International Conference), EFERIC (Entrepreneurship and Family Enterprise Research International Conference), EGTEIC (Environment, Green Technology and Engineering) and ESDEIC (Green and Circular Economy, Sustainable Development and Energy International Conference).

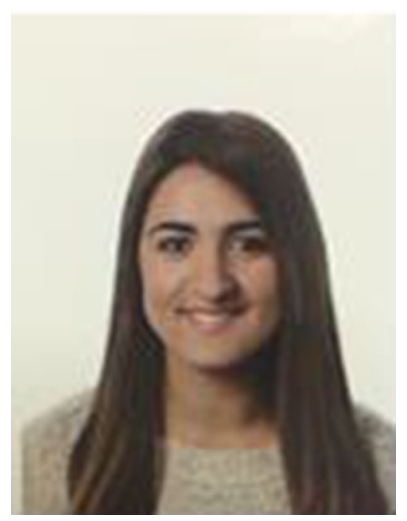

Ascensión Barroso Martinez She has recently published collaborative research work in impact factor journals as the International Journal of Environmental Research and Public Health, Tourism and Management Studies, Sustainability, Journal of Business Research, Journal of Family Business Strategy, European Journal of International Management, Intangible Capital Management Research: The Journal of the Iberoamerican Academy of Management and International Journal of Business Innovation and Research.

She collaborated in entrepreneurship training projects. She had several teaching visits in Sweeden, Czech Republic, Cuba and France. She participated in several prestigious conferences all over the world and research visit of more than 1 year in Portugal, Sweden and the UK and participated in regional and European research projects. She is a director of master degree, degree, doctoral theses, and dissertations works. 


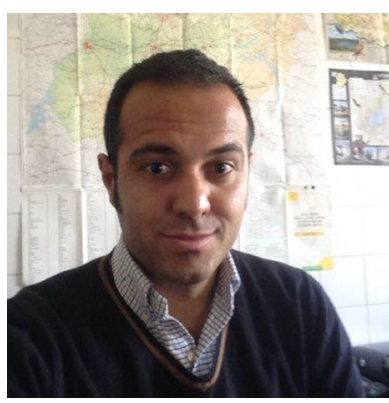

Santiago Fernández-Rodríguez $\mathrm{He}$ is the one responsible of the research group Aerobiology in Extremadura of the UEx, which studies the indoor and outdoor air quality with the ornamental sources of the cities evaluated through the aerobiological content to be applied in the environmental impact study. He participated in 40 JCR articles (19Q1, 9Q2, 10Q3 and 2Q4) collected in "Environmental Science, Medicine, Earth and Planetary Sciences and Engineering", among other areas. He had four teaching visits at the Universities of Évora, Coimbra and Perugia (2014-2018). He participated in three teaching innovation groups and in ten teaching innovation projects and in an organizing committee in two teaching innovation conferences.

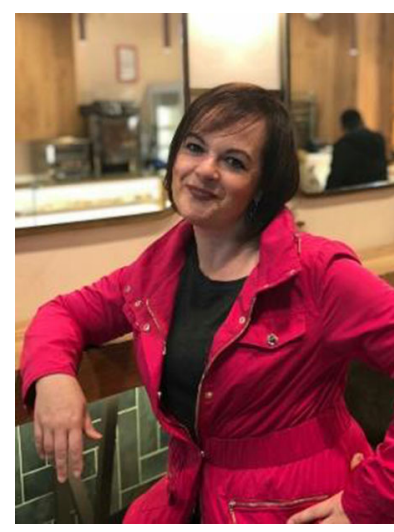

María Isabel SánchezHernández She is a lecturer and researcher in the Department of Business Management and Sociology at the School of Economics and Business Administration at the University of Extremadura, in Spain. She is an economist specialized in Corporate Social Responsibility and Sustainability, Ph.D. in Business Administration (University of Extremadura, Spain), MSc in Economics (University of Aberdeen, UK) and MBA in Organization and Human Resources Management (Polytechnic University of Madrid, Spain). She has contributed to the training of entrepreneurs and is involved in various innovative research projects aiming to foster circular economy and sustainable business in society. 